\title{
Standard of Care and Controversies in the Adjuvant Endocrine Treatment of Hormone-Responsive Early Breast Cancer
}

\author{
Dirk O. Bauerschlaga Nicolai Maass ${ }^{a} \quad$ Christian Schem ${ }^{b}$ \\ ${ }^{a}$ Klinik für Gynäkologie und Geburtshilfe, Uniklinikum RWTH Aachen, Germany \\ ${ }^{b}$ Klinik für Gynäkologie und Geburtshilfe, Universitätsklinikum Schleswig-Holstein, Campus Kiel, Germany
}

\section{Keywords}

Endocrine treatment - Tamoxifen - Aromatase inhibitor . Premenopausal status - Postmenopausal status .

CYP2D6 - Endocrine resistance

\section{Summary}

Hormone-responsive early breast cancer is a highly curable disease. In premenopausal women, tamoxifen (TAM) is still the standard treatment. Nowadays, up to 10 years of TAM can be safely administered, especially in women who remain premenopausal. Patients who are considered to be perimenopausal should be initially treated like premenopausal patients. Depending on their serum hormone levels, these patients can be safely switched to an aromatase inhibitor (Al) therapy once the estradiol (E2) and follicle-stimulating hormone (FSH) levels prove the established postmenopausal status. In postmenopausal women, several sequences of endocrine treatment are available. The Al therapy can be induced upfront or sequentially by switching from Tam to $\mathrm{Al}$ and vice versa. Extended endocrine therapy, by adding up to 5 years of letrozole after 5 years of TAM, has also been proven to be beneficial in certain patient subgroups. Genotyping of cytochromes such as CYP2D6 did not have any added value in identifying patients who are at higher risk of recurrence. Nevertheless, in all patients the side effects need to be given high consideration. New strategies developed to overcome endocrine resistance are tested in clinical studies. New co-administered drugs such as specific inhibitors of mammalian target of rapamycin (mTOR), Src, or phosphatidylinositol 3-kinase (PI3K) do improve endocrine responsiveness in metastatic disease and will eventually be introduced in the treatment of early breast cancer.

\section{KARGER}

Fax +497614520714

Information@Karger.com

www.karger.com (c) 2014 S. Karger GmbH, Freiburg

1661-3791/14/0094-0283\$39.50/0

Accessible online at:

www.karger.com/brc
Early breast cancer is a highly curable disease. It is therefore of utmost importance to choose the right therapeutic option in order to achieve this ultimate goal.

In most patients, the breast cancer is hormone receptor positive, meaning that at least $1 \%$ of the tumor cells express the estrogen receptor (ER) and/or the progesterone receptor $(\mathrm{PR})$ in the nucleolus.

Clarification of the menopausal status is a crucial issue in choosing the right treatment option. Due to different modes of action of tamoxifen (TAM) and aromatase inhibitors (AIs), the recommendations in pre- and postmenopausal women differ substantially.

The definition of the postmenopausal status is not absolutely clear. The latency phase is highly individual and patients in transition from the pre- to the postmenopausal status are considered as perimenopausal.

The definition for the postmenopausal status given by the $\mathrm{Na}$ tional Comprehensive Cancer Network (NCCN) is as follows:

- age over 60 years

- surgically removed ovaries

- age less than 60 years:

- amenorrheic for $\geq 12$ months in the absence of chemotherapy, TAM, toremifene or

- ovarian suppression; and follicle-stimulating hormone (FSH) and plasma estradiol in the postmenopausal range; if taking TAM or toremifene and $\leq 60$ years of age, then the FSH and plasma estradiol levels should be in the postmenopausal range.

\section{Treatment in Premenopausal Patients}

In premenopausal women, TAM remains the gold standard of care. However, the recommended duration of the adjuvant 
treatment has just recently been revisited, resulting in a new set of data in the ATLAS trial [1]. Over the last decades, 5 years of TAM was proven to reduce overall breast cancer recurrence and the mortality rate by about $50 \%$ and $30 \%$, respectively [2]. In patients younger than 50 years, the rate of recurrence was reduced by $45 \%$ and the mortality by $32 \%$. One other interesting finding was that a carryover effect for mortality reduction was detected, which grew steadily throughout the first 10 years, whereas the reduction in recurrence peaked within the first 5 years.

Davies et al. [1] found that an additional 5-year intake of TAM does improve breast cancer survival by $2.8 \%$, especially in the timeframe after the total of 10 years. One major concern is always whether this benefit outweighs the side effects such as thromboembolic events or even the induction of endometrial cancer due to partial agonistic effects on the endometrial layer. This increase in risk mostly affects patients older than 55 years. But premenopausal women do suffer from hot flashes and vaginal discharge. Similar results were demonstrated in the aTTom trial, also looking at the effects of extended endocrine therapy (EET); however, these data have not yet been fully published. Nevertheless, one should consider the tumor size and biology before offering an EET too generously. Importantly, TAM itself does not cause infertility; thus, patients should be advised to use non-hormonal contraceptives.

TAM is a member of the selective ER modulators (SERMs), which directly target the ER. Trials comparing combined treatment with TAM and gonadotropin-releasing hormone $(\mathrm{GnRH})$ analogs to TAM alone did not show any significant differences in overall survival (OS) or disease-free survival (DFS) [3]. For many years, GnRH analogs were additively applied in very young patients (less than 40 years of age). But, over time, it turned out that this additional suppression of the pituitary gonadal axis was overrated in high-risk patients who received adjuvant chemotherapy. Recently, Thurlimann et al. [4] have reported no benefit of 4 cycles of doxorubicin and cyclophosphamide given adjuvantly to lowrisk, node-positive, endocrine-responsive premenopausal patients, when added to GnRH analogs plus TAM. However, there are some caveats to this investigation, which was stopped early due to slow accrual. Only just more than half of the patients actually received GnRH analogs. Ovarian function suppression (OFS) in the other patients was induced either by surgical oophorectomy or by bilateral ovarian radiation. Also, this study was conducted before taxanes were given routinely in this clinical situation.

AIs are not recommended in premenopausal patients. This is because estrogen production in the ovaries is insufficiently suppressed by AIs alone. In case of TAM intolerability or recurrence, the combination of GnRH analogs and AIs is an option in the premenopausal situation. To further investigate the potential role of AIs in premenopausal women, 2 separate trials were initiated. In the TEXT trial, premenopausal pa- tients were randomized to receive either exemestane or TAM in combination with triptorelin for OFS. The Suppression of Ovarian Function Trial (SOFT) was designed to determine the role of OFS and that of AIs in patients who remained premenopausal. Due to low event rates, additional years of follow-up are required [5]. At the annual meeting of the American Society of Clinical Oncology (ASCO) in 2014, first results were presented. Ovarian suppression in combination with AIs or TAM is highly effective, with an advantage for the AIs. But these results have to be interpreted with caution since the comparative results with TAM alone have not yet been published; they are expected for this year's San Antonio Breast Cancer Symposium. Overall, these findings are in line with the results from the Austrian Breast and Colorectal Cancer Study Group (ABCSG) 12 study where virtually no difference was found between the two endocrine regimens.

In patients who became postmenopausal after 5 years of TAM and who are candidates for EET, 2 options are available. To begin with, it is not entirely clear which patients should receive an EET. Patients with tumor sizes over $15 \mathrm{~mm}$, poorly differentiated tumors, and/or nodal involvement are likely to benefit the most. In patients with well-differentiated and small-size tumors, an EET might be an overtreatment. But if a patient qualifies for EET, side effects and comorbidities have to be carefully taken into account in recommending the continuation of TAM or the switch to an AI on the basis of the MA.17 results. If the patient has 2 or more of the above-mentioned risk factors, the use of an AI seems to be beneficial.

Patients who are not clearly postmenopausal but are in transition, or premenopausal patients who received adjuvant chemotherapy and develop an amenorrhea, are considered perimenopausal. In these women, the endocrine treatment should be adjusted to the hormonal status at the time point of diagnosis. In general, TAM should be the first choice. After 2-3 years, an assessment of the estrogen and FSH levels can be performed to identify those patients that have become truly postmenopausal. Switching from TAM to a non-steroidal AI would be an option [6, 7]. In a recent update of the Italian Tamoxifen Anastrozol trial [8], after a median followup of 128 months, 94 and 71 events of relapse were reported in the TAM and anastrozole group, respectively. These results were statistically significant, but this advantage again did not translate into a superior survival of patients treated with the AI.

If patients remain premenopausal within the 2-3 years of TAM, the TAM therapy should be completed and patients can be offered to stay on TAM for another 5 years [1]. In case of the patient turning postmenopausal after 5 years and being at high risk of recurrence, e.g. with high nodal involvement, the addition of letrozole for up to 5 years has been proven to be beneficial in terms of DFS (hazard ratio (HR) 0.37) [9]. In 2013, a subgroup analysis of the MA.17 study cohort revealed differences in DFS, depending on the menopausal status at 
the time of study entry [10]. Patients who were premenopausal at the time of diagnosis had the highest benefit from the additional 5 years of letrozole with regard to DFS (HR 0.26). This benefit was more pronounced in node-positive patients, both in pre- and postmenopausal women at study entry. But, again, this advantage did not have a beneficial influence on OS.

\section{Treatment in Postmenopausal Patients}

In postmenopausal women, the endocrine therapy includes - besides TAM - steroidal and non-steroidal AIs. In several studies, AIs have been investigated looking at different schedules of AIs: upfront therapy $[6,11]$, switch $[6,7,12]$, inverse switch [6], and the extended therapy [9]. 3 third-generation AIs are currently available in the clinic. Anastrozole and letrozole are non-steroidal AIs whereas exemestane is based on a steroidal backbone. The adjuvant treatment with AIs led to an improved DFS; however, this advantage did not translate into a significantly improved OS. A face-to-face comparison of the non-steroidal AIs was initiated in 2007, but results are still not published. The challenge is to choose the right alternative option in the treatment of endocrine-responsive early breast cancer. The possible side effects with respect to the individual patient's background could be used as guiding factors.

TAM - especially in postmenopausal patients - is affiliated with an increased risk of thromboembolism and endometrial cancer. In the ATLAS trial where TAM was administered for 10 years, the relative risk to develop endometrial cancer was 1.74 and an absolute mortality increase of $0.2 \%$ was observed. For pulmonary embolism, the relative risk increased by 1.87 [1]. Some cases of impaired vision by accelerated cataract formation have also been described.

Its fewer side effects on the patient's bone health result in an advantage for TAM. The ATAC trial revealed a higher fracture rate in patients receiving anastrozole when compared to TAM, with an odds ratio of 1.33 [11].

In postmenopausal patients with hysterectomy and proven osteopenia or even osteoporosis and with favorable tumor biology and tumor size, a 5-year treatment with TAM is still a valid option. Nevertheless osteoporosis itself calls for proper treatment with bisphosphonates while the patient is under endocrine therapy. A bone density scan is recommended in patients starting on endocrine therapy, especially in case of an own or family history of osteoporosis.

For some patients, the effective option of extended therapy with an additional 5 years of TAM or letrozole is of especially high interest. Overall, besides endocrine treatment, the patients should be highly encouraged to perform moderate physical exercises 3 times a week on a regular basis. The increase in physical activity has a huge impact on breast cancer survival.
When inducing adjuvant endocrine treatment in a non-hysterectomized patient with a tumor of higher grading and larger size, AIs are favorable. Patients receiving AI treatment should be offered a bone density measurement before starting the AI and after 12 months of treatment [13]. Additional calcium and vitamin D intake is recommended as a preventive measure to lower the risk of decreased bone mineral density. For AI treatment, also a higher fracture rate has been reported [11], caused by the described loss in bone mineral density. This is of high interest for osteopenic patients or those even suffering from osteoporosis. This condition would indicate a therapy with bisphophonates such as clodronate per os or zoledronic acid intravenously.

The most often reported side effects of AI treatment are myalgia and arthralgia. These side effects are - besides the bone pain - the major reason for reduced compliance to the drug intake schedule in these patients. To avoid discontinuation, it seems important to provide the patients with information about possible side effects. To relieve the pain, non-steroidal antiphlogistics can be introduced. In cases of persistence, a change from a non-steroidal to a steroidal AI offers an alternative to continue the effective endocrine treatment. Up to date there are no data that support the idea of an extended AI therapy in analogy to the 10 -year intake of TAM.

\section{CYP2D6 Genotypes and Endocrine Resistance}

Many attempts have been undertaken to explore the impact of TAM metabolism by cytochrome P450 2D6 (CYP2D6). In initial reports, patients were defined as low or extensive metabolizers, showing different outcomes in DFS. The most recent reports dismiss this effect as not clinically relevant. Many pharmacogenetic studies have investigated the metabolism of TAM by especially looking at the CYP2D6 genotypes. In an analysis of the TEAM trial, in which patients were treated sequentially with TAM or exemestane, Dezentje et al. [14] did not find any association between the CYP2D6 phenotype (poor vs. extensive metabolizer) and DFS in the TAM treatment arm. Likewise, in patients included in the ATAC trial, no significant association between the genotypes of CYP2D6 or UDP-glucuronosyltransferase 2B7 (UGT2B7; an inactivator of endoxifen) was observed in the TAM group. Also no correlation was found in the anastrozole group [15].

\section{Endocrine Resistance}

The ER pathway plays a pivotal role in breast cancer development and progression. Endocrine therapy blocking the endocrine signal transduction is highly effective, but its effects are sometimes limited by intrinsic and acquired cellular resistance. Multiple mechanisms responsible for endocrine resistance have been proposed. Alterations in cell cycle and cell 
survival signaling molecules and the activation of escape pathways that can provide tumors with alternative proliferative and survival stimuli have been studied and targeted by new therapies. Especially the epidermal growth factor receptor (EGFR)/human epidermal growth factor receptor 2 (HER2) pathway has been associated with both experimental and clinical endocrine therapy resistance. New treatment combinations targeting both the ER and growth factor receptor signaling to block the crosstalk between these pathways and to eliminate escape routes have been proven highly effective in preclinical models and early phase II but also phase III trials. Cotargeting of the phosphatidylinositol 3-kinase (PI3K; e.g. by BKM120), mammalian target of rapamycin (mTOR; by everolimus), or Src pathways (by dasatinib) and the ER in ad- vanced breast cancer showed striking results, but also accounted for increased side effects in this endocrine therapy, which has in the past been considered as being more tolerable than chemotherapy. Therefore these clinical study results also highlight the need to better identify a priori those patients who are most likely to benefit from these specific cotargeting strategies upfront in early breast cancer. There is still a lot of progress needed in order to introduce cotargeted endocrine therapy in early breast cancer. In the future, new sequential approaches, better side effect management, and individualized therapy monitoring by companion diagnostic tests will probably support us in this matter. Until then, every treatment decision has to be carefully weighed with the patient.

\section{References}

1 Davies C, Pan H, Godwin J, Gray R, Arriagada R, Raina V, Abraham M, Medeiros Alencar VH, Badran A, Bonfill X, Bradbury J, Clarke M, Collins R, Davis SR, Delmestri A, Forbes JF, Haddad P, Hou MF, Inbar M, Khaled H, Kielanowska J, Kwan WH, Mathew BS, Mittra I, Muller B, Nicolucci A, Peralta O, Pernas F, Petruzelka L, Pienkowski T, Radhika R, Rajan B, Rubach MT, Tort S, Urrutia G, Valentini M, Wang Y, Peto R: Long-term effects of continuing adjuvant tamoxifen to 10 years versus stopping at 5 years after diagnosis of oestrogen receptor-positive breast cancer: ATLAS, a randomised trial. Lancet 2013;381:805-816.

2 Tamoxifen for early breast cancer: an overview of the randomised trials. Early Breast Cancer Trialists' Collaborative Group. Lancet 1998:351:1451-1467.

3 Cuzick J, Ambroisine L, Davidson N, Jakesz R, Kaufmann M, Regan M, Sainsbury R: Use of luteinising-hormone-releasing hormone agonists as adjuvant treatment in premenopausal patients with hormone-receptor-positive breast cancer: a metaanalysis of individual patient data from randomised adjuvant trials. Lancet 2007;369:1711-1723.

4 Thurlimann B, Price KN, Gelber RD, Holmberg SB, Crivellari D, Colleoni M, Collins J, Forbes JF, Castiglione-Gertsch M, Coates AS, Goldhirsch A: Is chemotherapy necessary for premenopausal women with lower-risk node-positive, endocrine responsive breast cancer? 10-year update of International Breast Cancer Study Group Trial 11-93. Breast Cancer Res Treat 2009;113:137-144.

$\checkmark 5$ Regan MM, Pagani O, Fleming GF, Walley BA, Price KN, Rabaglio M, Maibach R, Ruepp B, Coates AS, Goldhirsch A, Colleoni M, Gelber RD, Francis PA: Adjuvant treatment of premenopausal women with endocrine-responsive early breast cancer: design of the TEXT and SOFT trials. Breast 2013;22:1094-1100.
6 Regan MM, Neven P, Giobbie-Hurder A, Goldhirsch A, Ejlertsen B, Mauriac L, Forbes JF, Smith I, Lang I, Wardley A, Rabaglio M, Price KN, Gelber RD, Coates AS, Thurlimann B: Assessment of letrozole and tamoxifen alone and in sequence for postmenopausal women with steroid hormone receptor-positive breast cancer: the BIG 1-98 randomised clinical trial at 8.1 years median follow-up. Lancet Oncol 2011;12:1101-1108.

7 Dubsky PC, Jakesz R, Mlineritsch B, Postlberger S, Samonigg H, Kwasny W, Tausch C, Stoger H, Haider K, Fitzal F, Singer CF, Stierer M, Sevelda P, Luschin-Ebengreuth G, Taucher S, Rudas M, Bartsch R, Steger GG, Greil R, Filipcic L, Gnant M: Tamoxifen and anastrozole as a sequencing strategy: a randomized controlled trial in postmenopausal patients with endocrine-responsive early breast cancer from the Austrian Breast and Colorectal Cancer Study Group. J Clin Oncol 2012;30:722-728.

8 Boccardo F, Guglielmini P, Bordonaro R, Fini A, Massidda B, Porpiglia M, Roagna R, Serra P, Orzalesi L, Ucci G, Rubagotti A: Switching to anastrozole versus continued tamoxifen treatment of early breast cancer: long term results of the Italian Tamoxifen Anastrozole trial. Eur J Cancer 2013;49: 1546-1554.

-9 Goss PE, Ingle JN, Pater JL, Martino S, Robert NJ, Muss HB, Piccart MJ, Castiglione M, Shepherd LE, Pritchard KI, Livingston RB, Davidson NE, Norton L, Perez EA, Abrams JS, Cameron DA, Palmer MJ, Tu D: Late extended adjuvant treatment with letrozole improves outcome in women with earlystage breast cancer who complete 5 years of tamoxifen. J Clin Oncol 2008;26:1948-1955.
10 Goss PE, Ingle JN, Martino S, Robert NJ, Muss HB, Livingston RB, Davidson NE, Perez EA, Chavarri-Guerra Y, Cameron DA, Pritchard KI, Whelan T, Shepherd LE, Tu D: Impact of premenopausal status at breast cancer diagnosis in women entered on the placebo-controlled NCIC CTG MA17 trial of extended adjuvant letrozole. Ann Oncol 2013;24:355-361.

11 Cuzick J, Sestak I, Baum M, Buzdar A, Howell A, Dowsett M, Forbes JF: Effect of anastrozole and tamoxifen as adjuvant treatment for early-stage breast cancer: 10-year analysis of the ATAC trial. Lancet Oncol 2010;11:1135-1141.

12 Jonat W, Gnant M, Boccardo F, Kaufmann M, Rubagotti A, Zuna I, Greenwood M, Jakesz R: Effectiveness of switching from adjuvant tamoxifen to anastrozole in postmenopausal women with hormone-sensitive early-stage breast cancer: a metaanalysis. Lancet Oncol 2006;7:991-996.

13 Hadji P, Body JJ, Aapro MS, Brufsky A, Coleman RE, Guise T, Lipton A, Tubiana-Hulin M: Practical guidance for the management of aromatase inhibitor-associated bone loss. Ann Oncol 2008;19: 1407-1416.

14 Dezentje VO, van Schaik RH, Vletter-Bogaartz JM, van der Straaten T, Wessels JA, Kranenbarg EM, Berns EM, Seynaeve C, Putter H, van de Velde CJ, Nortier JW, Gelderblom H, Guchelaar HJ: CYP2D6 genotype in relation to tamoxifen efficacy in a Dutch cohort of the tamoxifen exemestane adjuvant multinational (TEAM) trial. Breast Cancer Res Treat 2013;140:363-373.

15 Rae JM, Drury S, Hayes DF, Stearns V, Thibert JN, Haynes BP, Salter J, Sestak I, Cuzick J, Dowsett M: CYP2D6 and UGT2B7 genotype and risk of recurrence in tamoxifen-treated breast cancer patients. J Natl Cancer Inst 2012;104:452-460. 